\title{
DEFORMATION MONITORING OF LARGE STRUCTURES BY GROUND-BASED SAR INTERFEROMETRY
}

\author{
Monitoramento de Deformação em Grandes Estruturas pela Interferometria SAR de base no \\ solo
}

\begin{abstract}
Zhiwei Qiu ${ }^{1,2}$
Jianping Yue ${ }^{1}$

Xueqin Wang ${ }^{1}$

Shun Yue ${ }^{1}$

${ }^{1}$ Hohai University, Earth Science and Engineering, Focheng west road 8, Nanjing, China, 211000. Email: qiuzhiwei-2008@163.com

${ }^{2}$ Henan University of Urban Construction, Pingdingshan 467036, China
\end{abstract}

\begin{abstract}
:
In this paper, a ground-based SAR interferometry technology was used to monitor major engineering. This technology has been recognized as a powerful tool for terrain monitoring and structural change detecting. Deformation monitoring for large project has been a hot issue among them. According to GBSAR interferometry principle and characteristics of IBIS system, the authors analysis the error sources of deformation monitoring, and experimentally extract atmospheric phase which should removed based on permanent scattered analysis. Atmospheric disturbance effect analysis is discussed in this paper, and an atmospheric correction method is proposed to remove atmospheric effect, then the effective displacement can be retrieved. Results from this approach have been compared with that from traditional method in this campaign, GBInSAR technology can be exploited successfully in deformation monitoring for major projects with high accuracy.
\end{abstract}

Keywords: Atmospheric effect, GBSAR interferometry, IBIS system, permanent scattered (PS). 
Resumo: Neste artigo foi utilizada a tecnologia de interferometria SAR ground-based para monitoramento de estruturas. Esta tecnologia é reconhecida como uma ferramenta ponderosa para monitoramento do terreno e para detecção de alterações estruturais. $\mathrm{O}$ monitoramento de deformações em grandes projetos tem sido um tópico importante. De acordo com o princípio de interferometria GBSAR e das características do sistema IBIS os autores analisaram as fontes de erros no monitoramento de deformações, e extraíram experimentalmente a fase atmosférica baseado na análise de dispersão. A análise do efeito atmosférico é discutida neste artigo e propõe-se um método de correção atmosférica para remove-lo, de modo que o deslocamento efetivo possa ser obtido. Os resultados desta abordagem foram comparados com os métodos tradicionais nesta campanha e conclui-se que a tecnologia GBInSAR pode ser utilizada no monitoramento de grandes projetos com alta acurácia.

Palavras-chave: Efeito Atmosférico, Interferometria GBSAR, sistema IBIS, Dispersão permanente.

\section{Introduction}

Ground-based SAR system can receive the images for illuminated area by active imaging capability. Synthetic aperture radar and step-frequency continuous wave technology are employed to improve the special resolution in azimuth and rang direction(Yue Jianping, 2007). Interferometry technique can improve the accuracy on a fine resolution map of the scene. Typical applications are: landslide(Strozzi T, 2005;Noferini L, 2007;Luzi G,2009), glaciers(Luzi G,2007), the dam(Mario A,2008), building(D.Tarchi,2000) and bridges(Devis Dei,2009) and earthquake, volcanic hazard assessment, land subsidence monitoring(Pipia L,2007). GBInSAR with high precision, low cost, special continuity is a new approach for monitoring; its high sampling frequency is sensitive to the movements of architectural structures such as bridges and dams in real time(Qiu Zhiwei, 2010). This technique overcomes deficiencies belonged to spaceborne SAR such as spatial and temporal decorrelation, low resolution(Liao Mingsheng, 2003).

The research of deformation monitoring with ground-based SAR technology began in 1999, the monitoring experiment for a dam was accomplished by Tarchi et al. who published the first article about that. Leva et al. acquired landslide monitoring data in Australia in 2003 by using GBInSAR and GPS simultaneously. Combined with GPS measurement data, GBInSAR accuracy can be improved in rapid physical object deformation monitoring(Leva D,2003). In 2006, Massimiliano Pieraccini et al. analyzed the error sources of landslide monitoring in Italy, and permanent scatterer technology was employed in this paper to reduce the atmospheric effect and temporal decorelation. Kazunori Takahashi et al. monitored mountain landslide named as Kurikoma in Japan, a high-precision landslide displacement field was established with mountain DEM(Kazunori Takahashi,2013). In 2007, G.Bernardini monitored the bridge vibration by using GBSAR measurement system IBIS, the difference compared with rates obtained by traditional method is within $0.5 \mathrm{~mm} / \mathrm{sec}$ (G. Bernardini, 2007). In 2009, Devis et al. calculated the bridge deflection and torsion by using radar interferometry technique(Devis Dei,2009). In 2007, Luca 
Pipia in Spain carried out mining subsidence monitoring by GBInSAR with different polarization, this experiment proved the comprehensive utilization of $\mathrm{HH}$ and $\mathrm{VV}$ polarization image can extract accurate stable point(Linhsia Noferin,2007).

GBInSAR technology has been largely used in interference applications in recent years, technology defects such as atmospheric effects, temporal and special decorrelation become more prominent. In 2004, Guido Luzi et al. analyzed the decorrelation caused by baseline or other factors combined with GBInSAR monitoring data for landslide somewhere, and proposed atmospheric effects can be eliminated through the PS points. In 2005, Linhsia Noterini pointed out the true deformation values were submerged in phase errors caused by atmospheric disturbance for valley monitoring data, then the effective displacement could be extracted by meteorological correction for GBInSAR data with PS technique(Noferini L,2005). In 2006, Massimiliano Pieraccini et al. used GBInSAR technology to monitor the landslide somewhere unstable, eliminated the effect caused by temporal and meteorological decorrelation through PS technique, and verified the effectiveness of PS in GBInSAR.

\section{GBInSAR system IBIS and its working principle}

The displacement between target and radar center along the line of sight can be calculated by the interferogram derived from two GB-SAR images. The two dimensional image is produced by synthetic aperture radar technique, the range resolution is improved by SF-CW, and the deformation information can be extracted from interference phase difference, which is working principle for GBInSAR.

IBIS (Image by Interferometric Survey) used for monitoring illuminated targets displacement in long distance is ground-based microwave interferometer with active imaging capability. IBIS-L is novel radar which works based on microwave interferometry technique (Figure 1). Measurement distance is up to $4 \mathrm{~km}$, and its accuracy up to $0.1 \mathrm{~mm}$. Compared with GPS, this equipment working in almost all weather conditions continuously is easier to be installed. The system consists of step-frequency continuous-wave (SF-CW), synthetic aperture radar (SAR) and interferometry technology to obtain two-dimensional image of observed area. The phase variation can be extracted for monitoring. The definition of SF-CW and synthetic aperture radar technology will be explained below briefly. 


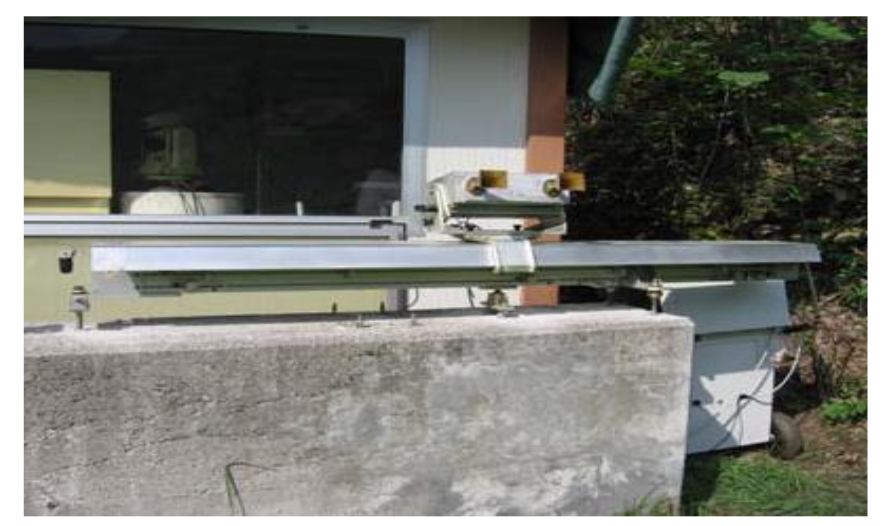

Figure 1: Micro-deformation monitoring system IBIS.

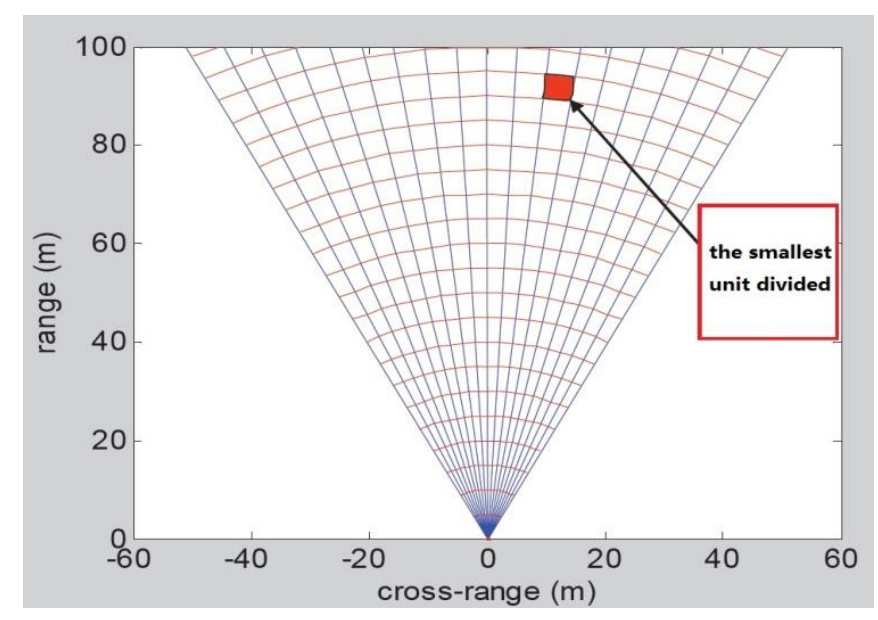

Figure 2: SF-CW technology.

\subsection{SF-CW technology}

Step-frequency continuous-wave (SF-CW) technology means radar system can produce a group of electromagnetic wave with different frequency in order to guarantee long distance transmission for electromagnetic wave during sweep time. This technology also provides high resolution in range direction for radar. If the max frequency bandwidth is $3 \times 10^{8}$, so the range resolution calculated by formula $\triangle \mathrm{r}=\mathrm{C} / 2 \mathrm{~B}$ is 0.5 meter. This means that every 0.5 meters of monitoring area is divided into one unit along the radial direction (Figure 2). 


\subsection{Synthetic Aperture Radar (SAR) technology}

Synthetic aperture technology is actually a Doppler analysis technology. The Doppler shift between different scatters with same range can be acquired by radar motion to improve azimuth resolution. In brief, the synthetic aperture technique is to use a real antenna with small motion as a long one, named as "synthetic aperture".

\section{Atmospheric disturbance analysis}

As the displacement can be extracted from interference phase received by Interferometry SAR, the phase quality affected by decorrelation is most important factor for deformation monitoring. The decorrelation of space borne radar is due to: a. geometric decorrelation caused by baseline; b. decorrelation caused by doppler shift; c. temporal decorrelation caused by revisiting period or temperature, meteorological condition. Although the measurement principle of GBInSAR is same with space-borne SAR in essence, the first and second one can be ignored because there is no baseline for GBSAR. Therefore, the temporal decorrelation caused by atmospheric disturbance is the key factor to improve phase quality for GBInSAR(He Min,2005;Huang Qihuang,2011).

Atmospheric refractivity $n$ changing with temporal and special distribution is the source of phase error due to atmospheric disturbance. Firstly, we can suppose radar frequency as $f$, the echo phase of the target located with a distance $r$ from radar antenna center can be expressed as(Strozzi T,2005):

$$
\varphi(t)=\frac{4 \pi f}{c} \int n(r, t) d r
$$

In Equation 1, $c$ is the propagation speed of radar wave in vacuum, refractivity $n$ is the function of time $t$ and range $r$. If the range $R$ between static target and radar is constant, refractivity $n$ only has relation with time $t$, the echo phase difference between times $t_{1}$ and $t_{2}$ can be expressed as:

$$
\Delta \varphi=\varphi\left(t_{2}\right)-\varphi\left(t_{1}\right)=\frac{4 \pi f R}{c}\left[n\left(t_{2}\right)-n\left(t_{1}\right)\right]
$$

The phase difference $\Delta \varphi$ is interference phase contributed by atmospheric disturbance. If the atmospheric conditions in time $t_{1}$ and $t_{2}$ are identical totally, the phase difference will be zero. However, the atmospheric condition is definitely not the same in different time. Therefore, this error would not be zero and should be corrected. 
GBInSAR signal once travels in troposphere, refractivity $n$ is the function of degree Kelvin $T$, atmospheric pressure $P$ and humidity $H$. The refractivity is very close to 1 as usual, so the refraction $N$ always takes place of the refractivity in electromagnetic wave propagation. The relation between them can be expressed as(L Pipia,2008):

$$
N=(n-1) \times 10^{6}
$$

Tropospheric delay can be divided into two components, dry $N_{d r y}$ and wet $N_{\text {wet }}$. The refraction $N$ can stated as:

$$
N=N(P, T, H)=N_{d y y}+N_{\text {wet }}=0.2589 \frac{P_{d}}{T}+\left(71.7+\frac{3.744 \times 10^{5}}{T}\right) \frac{e}{T}
$$

In Equation $4, P$ is total atmospheric pressure, $P_{d}$ is dry atmospheric pressure, $e$ is water vapor pressure, the unit of them is mbar. The relation between them is $P_{d}=P-e$, the water vapor pressure can be expressed as ( $e_{s a t}$ is standard vapor pressure saturation):

$$
e(T, H)=\frac{H}{100} \cdot e_{\text {sat }}(T)=\frac{H}{100} \cdot 6.1016 \times 10^{\left(\frac{7.5 T}{T+237.3}\right)}
$$

We can see that dry delay component has relation to total atmospheric pressure $P$ and degree Kelvin $T$, and wet delay component has relation to water vapor pressure $e$ and degree Kelvin $T$. As the water vapor distributions in troposphere vary in time and space greatly, wet delay component is main factor of atmospheric effect.

Therefore, phase difference caused by atmospheric effect is a function composed of range $R$ and atmospheric refractivity difference $\Delta n_{a t m}$. Supposed the central frequency is $2 \mathrm{GHz}$, the error curves are shown in Figure 3. The error caused by atmospheric effect is up to millimeter level when the atmospheric refractive difference increases with volume $10^{-5}$, and the displacement is proportional to range, so we should take measures on the atmospheric effect correction (L Pipia,2008).

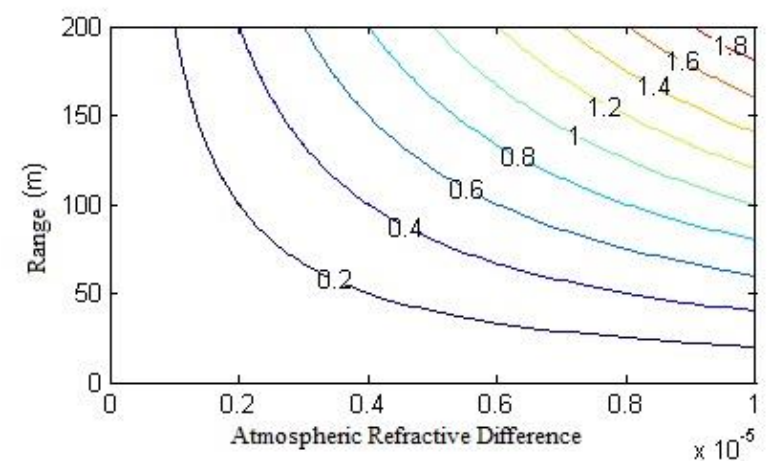

Figure 3: Atmospheric disturbance effect for GBsar.

Bol. Ciênc. Geod., sec. Artigos, Curitiba, v. 22, nº1, p.35 -53, jan-mar, 2016. 


\section{Artificial control point atmospheric correction method}

Stable artificial targets was placed in illuminated area before measurement, artificial control point correction method can eliminate the atmospheric disturbance by analyzing interference phase of these control point targets. Spain's L.Pipia ${ }^{21}$ and South Korea's H.Lee ${ }^{22}$ et al. arranged a stable metal reflector as artificial control points in observation region. The atmospheric effect were restricted by these points, the errors were rectified well. The stable artificial target can be regarded as a special PS point, and the parameters of the point can be accurately measured, processed simply. Therefore this method of atmospheric effects correction will be accomplished in our experiment, and then we will analyze this method.

Supposed $\varphi_{\text {atm }}(r, t)$ stands for phase error caused by atmospheric effect, the interference phase can be expressed as Equation 6 without considering the influence due to the vibration of scatterers and the noise caused by system.

$$
\varphi(r, t)=\varphi_{\text {dis }}(r, t)+\varphi_{\text {atm }}(r, t)
$$

In Equation 6, $\varphi_{\text {dis }}(r, t)$ means interference phase due to displacement, this value would be zero for static target. If the illuminated region is small scale, this phase model is linear:

$$
\varphi_{\text {atm }}(r, t)=a \cdot r
$$

The phase $\varphi_{\text {dis }}(r, t)$ is zero for artificial target without movements, $\hat{a}$ is the estimated value of coefficient $a$ can be expressed as:

$$
\hat{a}=\varphi_{0} / r
$$

The average value of a few control points can be calculated to improve the estimation accuracy as usual, other monitoring targets will be corrected with this value, $\varphi_{\text {corr }}(r, t)$ interference phase after correction is:

$$
\varphi_{\text {corr }}(r, t)=\varphi(r, t)-\hat{a}(t) \cdot r
$$

When the monitoring region is large scale and complex, the interference phase due to atmospheric effect which is nonlinear with the range $r$ can be expressed by quadratic function:

$$
\varphi_{\text {atm }}(r, t)=a_{1} \cdot r+a_{2} \cdot r^{2}
$$

The equation above can be solved by two stable artificial targets at least, the coefficients $a_{1}$ and $a_{2}$ will be calculated for atmosphere correction. Finally, the phase after correction is: 


$$
\varphi_{\text {corr }}(r, t)=\varphi(r, t)-\hat{a}_{1}(t) \cdot r-\hat{a}_{2}(t) \cdot r^{2}
$$

\subsection{Atmospheric correction experiment}

This experiment platform is IBIS system (see the section 2.3), artificial targets observed are reflector with three corners. Artificial control point atmospheric correction method is employed to eliminate atmospheric disturbance here.

Table 1: System parameters of IBIS

\begin{tabular}{ll}
\hline Parameter name & Parameter value \\
\hline Target Distance & $1-100 \mathrm{~m}$ \\
Bandwidth & $200 \mathrm{MHz}$ \\
Central Frequency & $17.0 \mathrm{GHz}$ \\
Range Resolution & $0.5 \mathrm{~m}$ \\
Measurement Accuracy & $0.01 \mathrm{~mm} / 0.1 \mathrm{~mm}$ \\
Max Samples & $200 \mathrm{~Hz}$ \\
\hline
\end{tabular}

The target distance is within $100 \mathrm{~m}$, the frequency center is $16.9 \mathrm{GHz}$, and wavelength is $17.6 \mathrm{~mm}$. The range resolution is $0.5 \mathrm{~m}$, and the dynamic monitoring measurement accuracy is $0.01 \mathrm{~mm}$, static monitoring measurement precision is $0.1 \mathrm{~mm}$. Other system parameters of IBIS are shown in Table 1.

Test site is Stone City along the Qinhuai River in Nanjing as shown in Figure 4, two corner reflectors CR1 and CR2 was arranged along the bank of this river. 24 IBIS measurements were received during the time from 10:00 to 17:00, the reflector CR2 was static all the time and the other had displacement with a few millimeters recorded by venire caliper in this experiment.

Figure 5 describes the range profile of IBIS data, the $\mathrm{X}$ axis means pixels (pixel resolution is $0.5 \mathrm{~m}$ ), and $\mathrm{Y}$ axis means the reflectivity. The accurate distance of corner reflectors and the piers are measured automatically by Georobot, the location of these points are demonstrated in Figure 5 .

Bol. Ciênc. Geod., sec. Artigos, Curitiba, v. 22, no1, p.35 -53, jan-mar, 2016. 

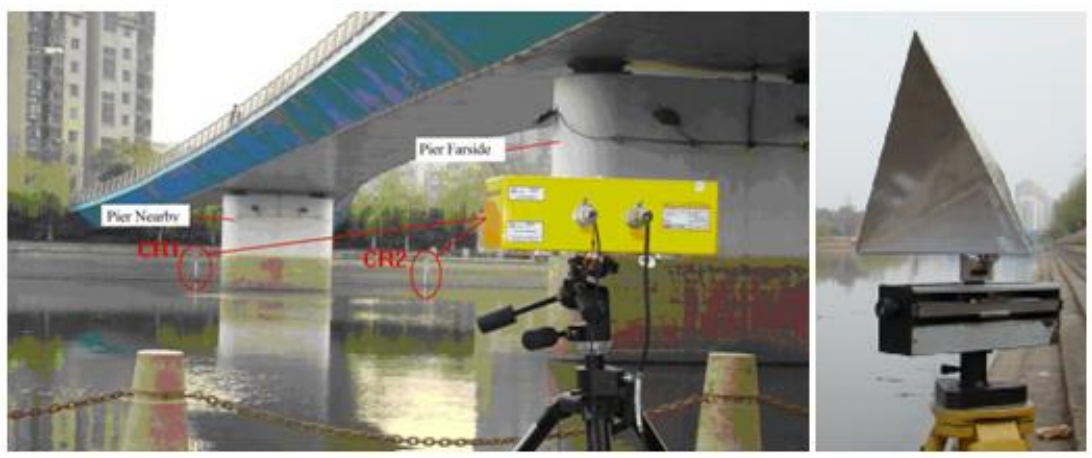

Figure 4: Atmosphere disturbance experiment scene correction and corner reflector.

Thermal SNR - atmospheric correction

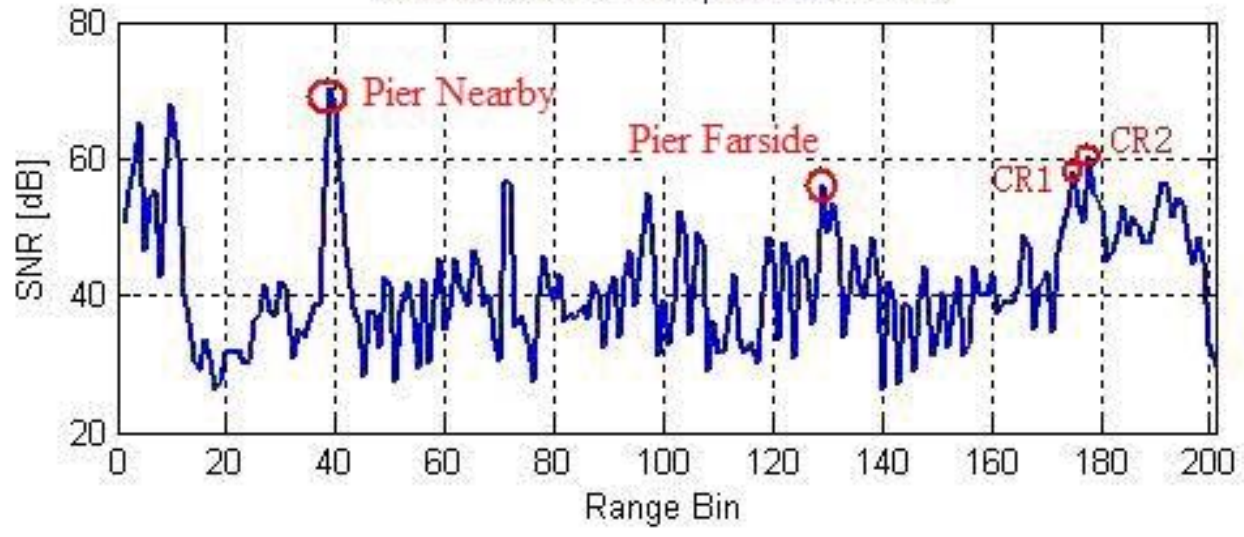

Figure 5: The range profile of IBIS data.

The atmospheric variation for illuminated area during data acquisition is drawn in Figure 6 and Figure 7, the atmosphere pressure of the scene was kept within $1006 \mathrm{hPa}$ to $1010 \mathrm{hPa}$, the temperature varied from $25^{\circ} \mathrm{C}$ to $30{ }^{\circ} \mathrm{C}$, and relative humidity was from $39 \%$ to $47 \%$. This measuring system has strong stability, the phase error caused by system and frequency shift can be ignored. As the corner reflectors are stable scatterers, phase error due to scattering characteristic is also negligible. Therefore, it can be considered that the interference phase is mainly caused by the atmospheric effect for stable artificial point target CR2 and the piers, but the interference phase for CR1 is influenced by the target displacement and atmospheric effect. 


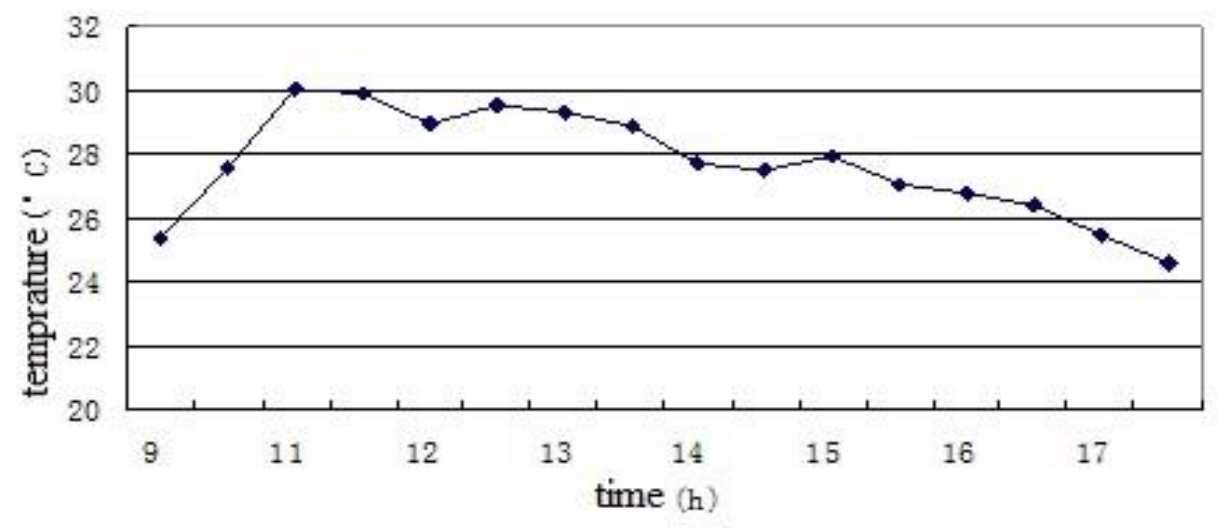

Figure 6: Temperature variation of the scene.

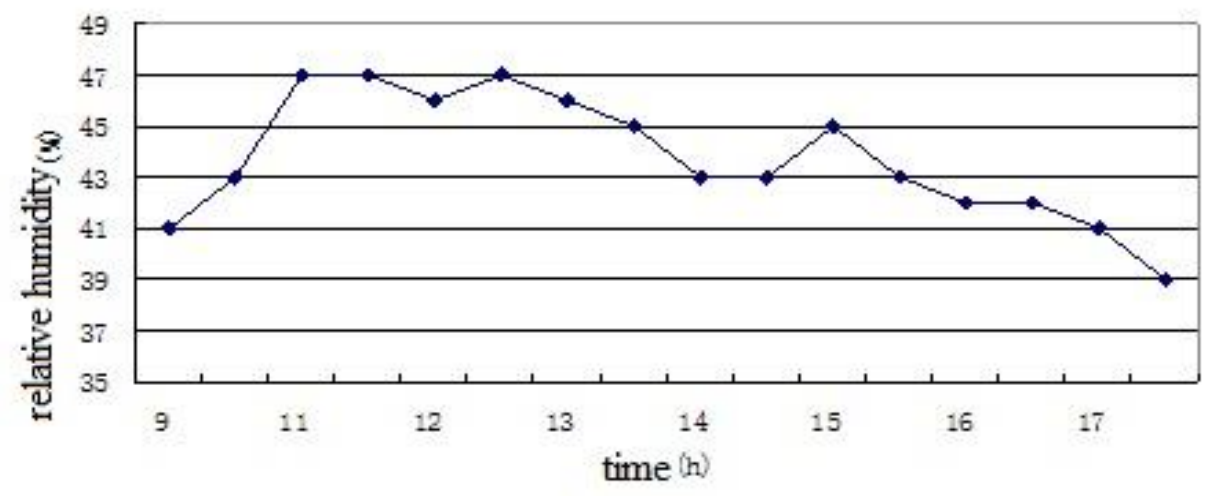

Figure 7: Relative humidity variation of the scene.

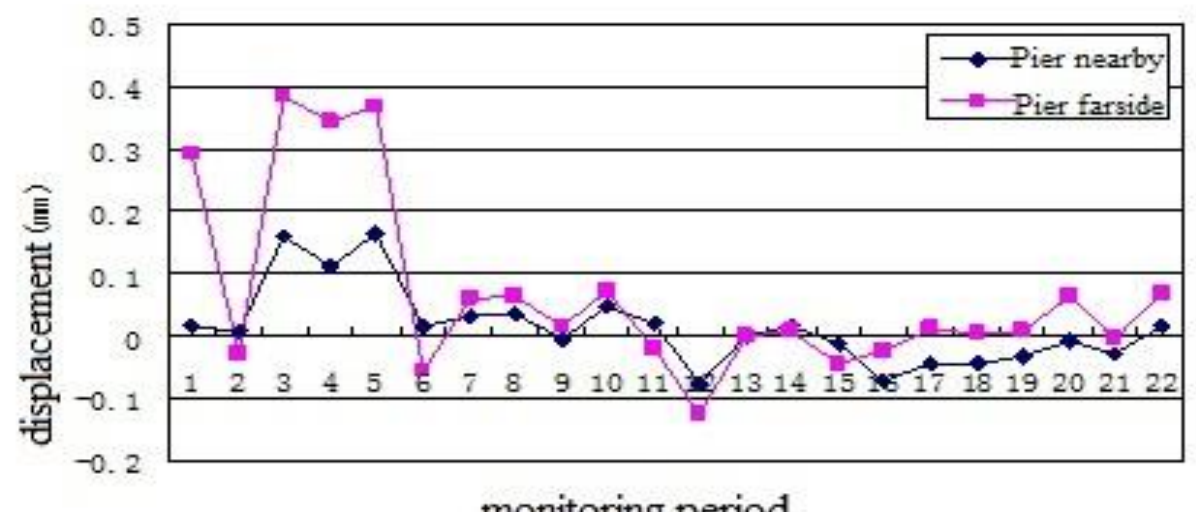

monitoring period

Figure 8: Displacement diagram for pier nearby and farside.

Bol. Ciênc. Geod., sec. Artigos, Curitiba, v. 22, no1, p.35 -53, jan-mar, 2016. 
For noise reduction, the displacements of each target during observation period are averaged, and the processed displacements for piers nearby and farside are drawn according to the monitoring period in Figure 8. Because the piers are stable and unshakable, the displacements measured for piers can be recognized as the phase error caused by atmospheric effects which is proportional to the distance, pier farside has greater variations than nearby obviously.

Since the scene is relatively small, the atmospheric effect factor $a$ can be estimated from Equation 7. The "distant pier" and "pier nearby" can be seen as the stable control point to estimate atmospheric influence factor. After taking the average of these two estimations as a regional atmospheric influence factor, coarse phase received by IBIS can be rectified by Equation 9. After atmospheric influence factors have been finished, the displacements before and after atmospheric correction for CR2 with the time series can be given in Equation 6.

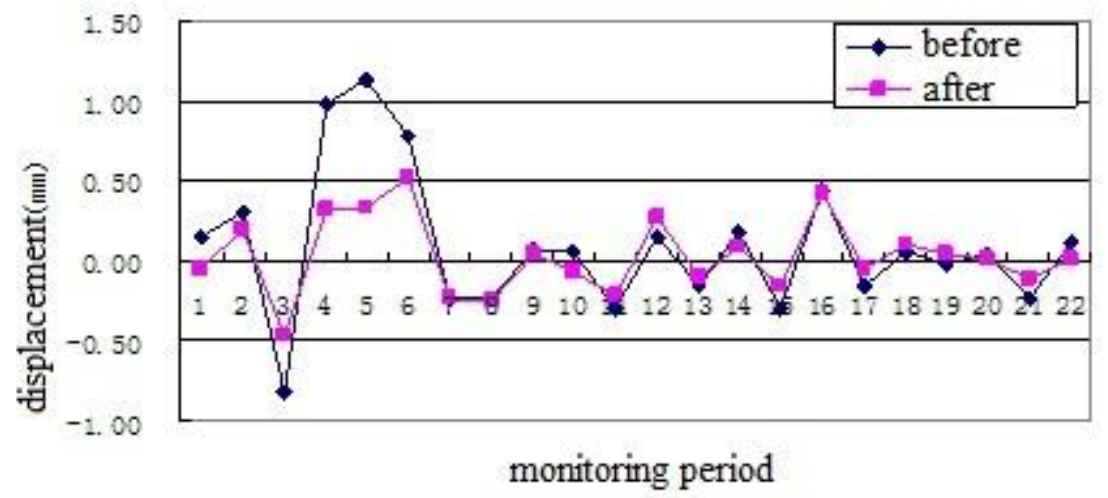

Figure 9: Displacement with atmospheric correction before and after for CR2.

Since the corner reflector CR2 is static, and the displacement should be zero, the displacement value is the observation error induced by atmospheric disturbance. After data analysis combined with statistical data in Table 2, atmospheric effect through atmospheric correction can be reduced by artificial control point atmosphere correction method.

Table 2: The statistical error of CR2 with atmospheric correction before and after

\begin{tabular}{llll}
\hline & MEAN & RMSE & MAX \\
\hline BEFORE & $0.31 \mathrm{~mm}$ & $\pm 0.32 \mathrm{~mm}$ & $1.13 \mathrm{~mm}$ \\
AFTER & $0.19 \mathrm{~mm}$ & $\pm 0.15 \mathrm{~mm}$ & $0.52 \mathrm{~mm}$ \\
\hline
\end{tabular}

Using the points of piers farside and nearby and CR2 after atmospheric correction as the control point, the target CR1 can be corrected with atmospheric correction. 


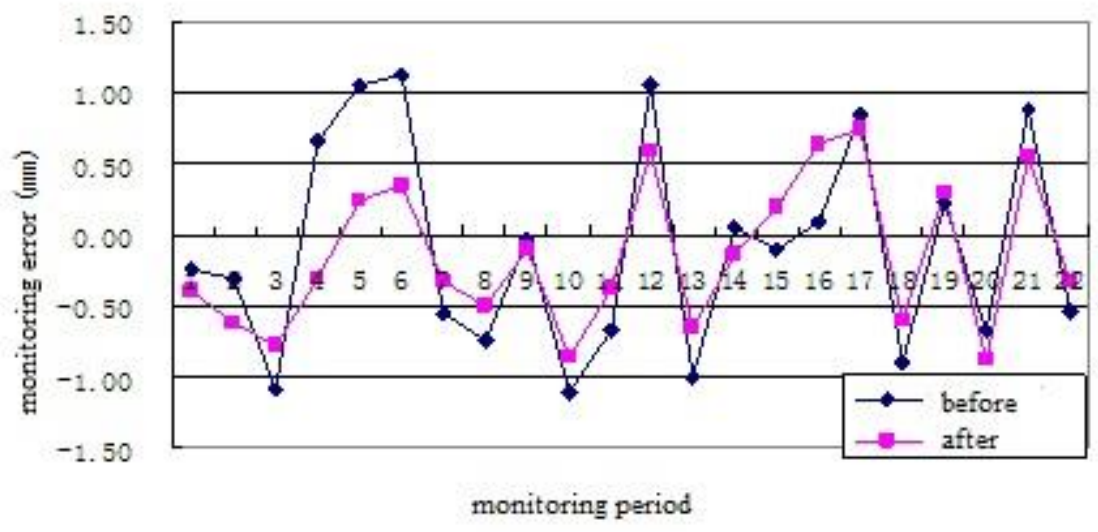

Figure 10: Displacement atmospheric correction before and after for CR1.

Static monitoring model is adopted by IBIS system, precision is $\pm 0.1 \mathrm{~mm}$. Corner reflectors with rail and venire caliper are installed with accuracy of $0.02 \mathrm{~mm}$, much higher than that of IBIS, so that the displacement measured by venire caliper can be seen as true value. Difference of these two values can be seen as the monitoring error of IBIS system. The monitoring error is shown in Figure 10, and statistical data is shown in Table 3. The statistical results show that the measure accuracy after atmospheric correction is improved greatly, and the max error could be controlled within $1 \mathrm{~mm}$.

Table 3: The statistical error of CR1 atmospheric correction before and after.

\begin{tabular}{llll}
\hline & MEAN & RMSE & MAX \\
\hline BEFORE & $0.54 \mathrm{~mm}$ & $\pm 0.52 \mathrm{~mm}$ & $1.12 \mathrm{~mm}$ \\
AFTER & $0.46 \mathrm{~mm}$ & $\pm 0.21 \mathrm{~mm}$ & $0.73 \mathrm{~mm}$ \\
\hline
\end{tabular}

\section{Dam deformation monitoring}

A measurement campaign was tailored for testing the capacity of the GBSAR system for dam deformation monitoring. This campaign was carried out for Hegeyan Dam (see in Figure 11) built on the Qing river near Changyang County in Hubei Province, and total reservoir capacity is 3.4 billion cubic meter. This reservoir was built in 1994 with installed capacity of 1.212 million KW. This dam is hyperbolic gravity arch dam with height of 151 meters, length of 653.5 meters, and elevation of 206 meters. The dam foundation is composed of limestone formed in Cambrian period, and the rocks on the dam shoulders are composed of limestone and shale interbred. 


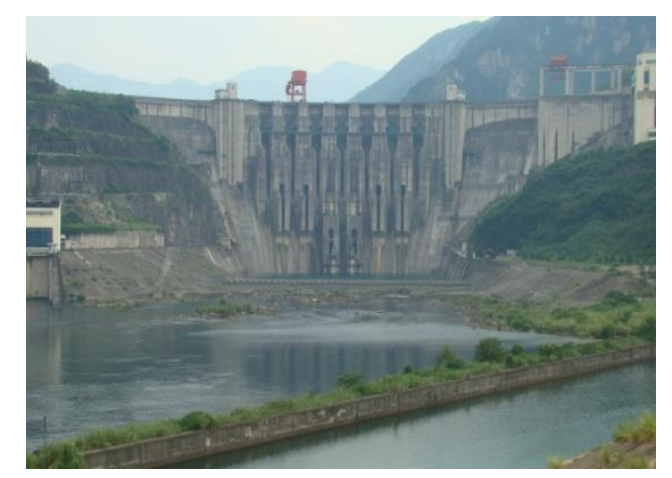

Figure 11: Dam of Hegeyan

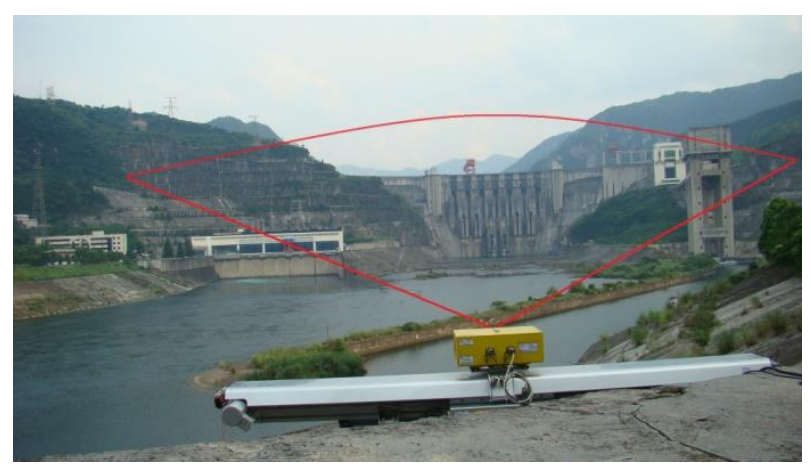

Figure 12: IBIS-L equipment and the scenario from the radar view

Constantly this structure was monitored during the time from July 1230 to 31, 2013. The device works in the Ku-band with a central wavelength of about $1.7 \mathrm{~cm}$ and is able to achieve a maximum cross-range resolution of about 4.5 mard. About 267 synthetic images was produced during this test campaign, and the revisiting interval was about $5 \mathrm{~min}$. Figure 12 depicts the IBIS-L equipment and the relative position between the dam and the IBIS. The maximum illuminated distance is 4 kilometers, and the maximum observation distance in this campaign is about $1.3 \mathrm{~km}$. The ground where the radar was placed on has stable geological structure. There were no obstructions between equipment and dam, so the illuminated scene covers the whole dam body and the surroundings.

\subsection{Materials and methods}

Before measurement data processing, the data collected by IBIS-L system was analyzed at first. The Figure 13 describes reflection power for the illuminated area, the monitor system can accurately receive radar reflection information from the scenario include the whole dam. The bedrock, riverbank and power station also can be identified clearly from the reflection power map. Shown in Figure 14 signal-to-noise ratio on the surface of the dam body were all over 15 
$\mathrm{db}$, correlation coefficients above 0.7 (Figure 15), and the phase stability above 3.0(Figure 16). Therefore, IBIS system was able to collect radar reflection information of structure surface, and this device has high reliability.

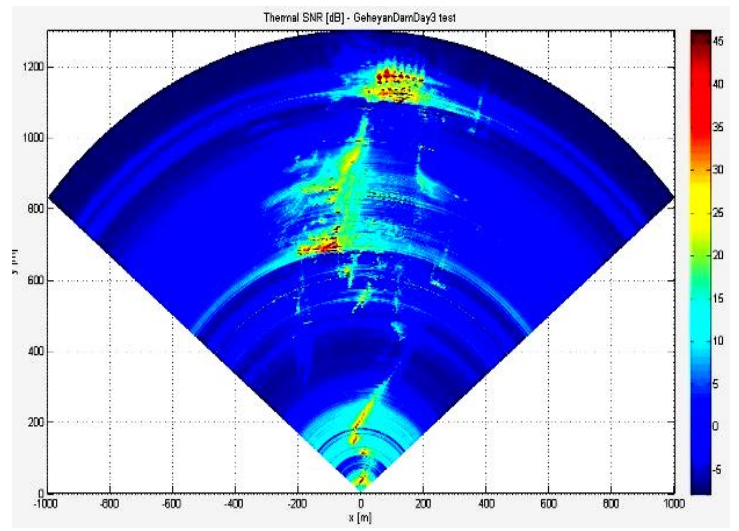

Figure 13: The reflection power map.

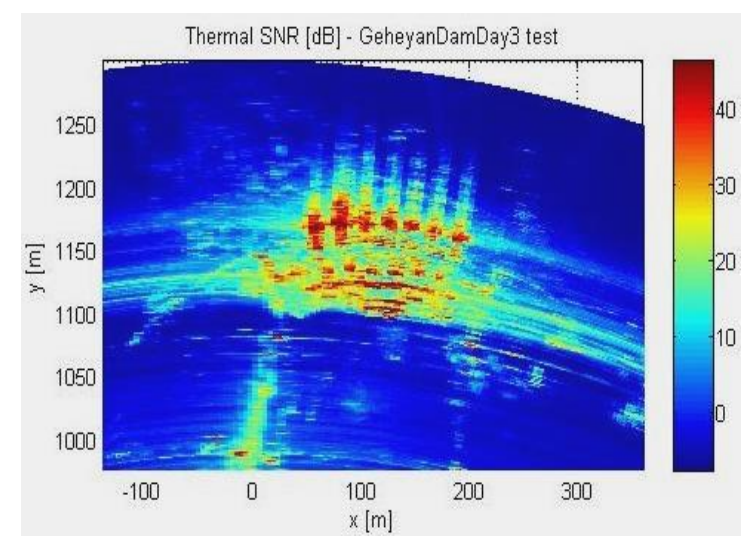

Figure 14: The signal-to-noise ratio of dam.

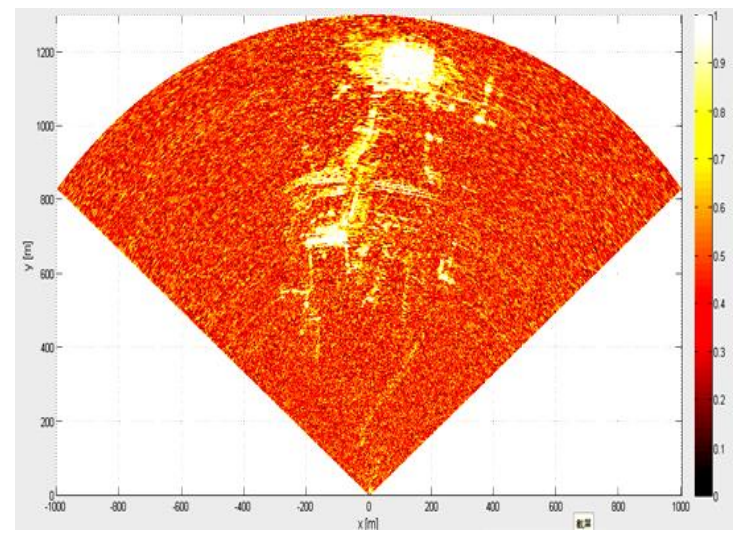

Figure 15: The coherent coefficient map.

Bol. Ciênc. Geod., sec. Artigos, Curitiba, v. 22, no1, p.35 -53, jan-mar, 2016. 


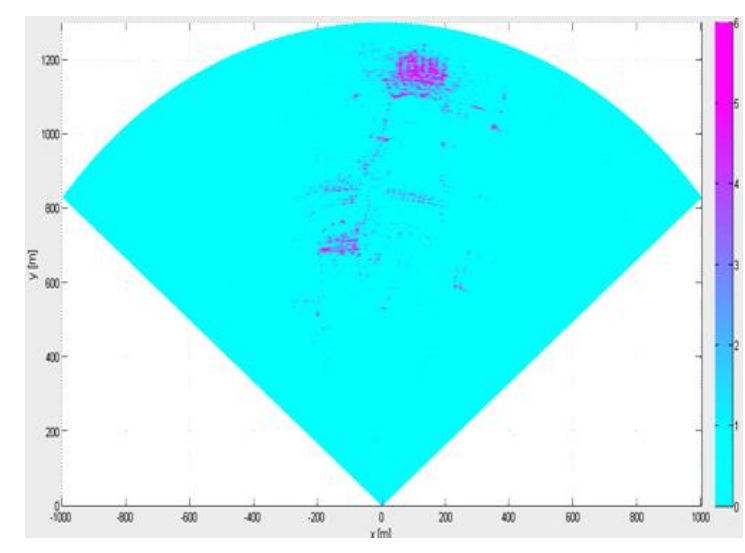

Figure 16: The phase stability map.

Three points located on the two sides of the bedrock were chosen as ground control point in this test, which has no displacement during the experiment. Other 13 feature points which should be good enough to be representative were selected elaborately for dam monitoring. Therefore, as these points in Figure 17 already showed were distributed on the dam of the upper, middle and lower position. As the ground control points were stable, the observed displacement was mainly derived by atmospheric disturbance. This error can be removed by stripped these displacement variation according to PS approach, and then the dam surface deformation can be calculated. Here a limited group of 13 scatterers chosen as feature points of structure surface were carried out for displacement variation analysis.

From start illuminated time to 17:38, some points had variables within $4 \mathrm{~mm}$ except a few points that were stable which were shown in Figure 18. At 18:05, the whole structure body moved about $4 \mathrm{~mm}$ linear deformation toward radar point, then the dam returned to its original state. Until 19:58, the dam had about $3 \mathrm{~mm}$ deformation close to radar. At 10:21 in 31 the dam body had about $1 \mathrm{~mm}$ deformation away from the radar station, and then the dam was stable. To 10:53, the dam was subjected to external forces generated $5.3 \mathrm{~mm}$ deformation towards the radar. After 11:20 the dam returned to the original state, the displacement of dam was less than $1 \mathrm{~mm}$ compared with original state. According to the deformation data analysis above, the dam has stable structure in conclusion. 


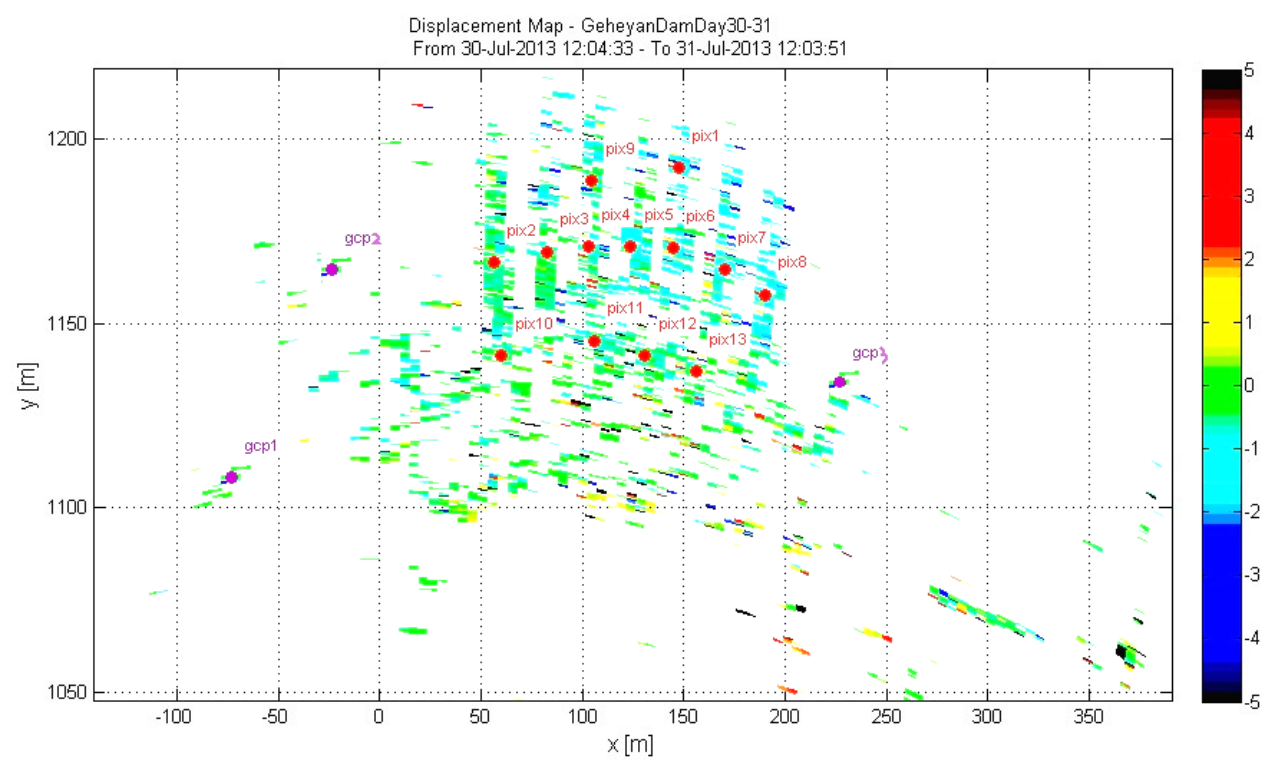

Figure 17: The false color map of LOS displacement for the dam.

The vertical measurement was also carried out for verification during GBSAR monitoring period. One point was chosen from dam foundation as stable point according to the basic principle of vertical monitoring. Therefore, measurement processed and vertical results were not able to be compared directly, even the data received by IBIS is the displacement along line of sight. Firstly, the LOS displacement should be projected along vertical direction ${ }^{23}$, and then the difference can be calculated by using the displacements from dam body point and bottom point (Figure 19). The difference between two methods of observation error can be restricted within $\pm 2 \mathrm{~mm}$, which might be caused by the existence of residual error such as atmospheric disturbance. Verification results show that this monitoring method is reliable to monitor dam deformation by using ground-based radar. Results from this atmospheric correction method have been compared with that from traditional method, GBInSAR technique can be applied in deformation monitoring for large water conservancy projects such as dam.

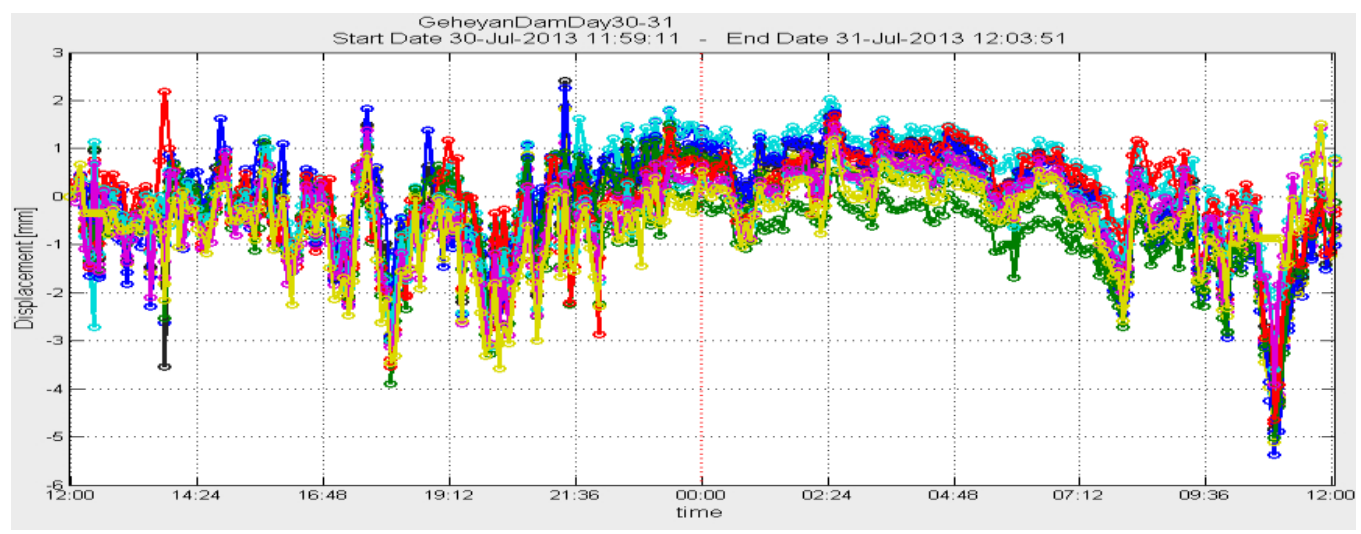

Figure 18: The time-LOS displacement diagram of feature points. 


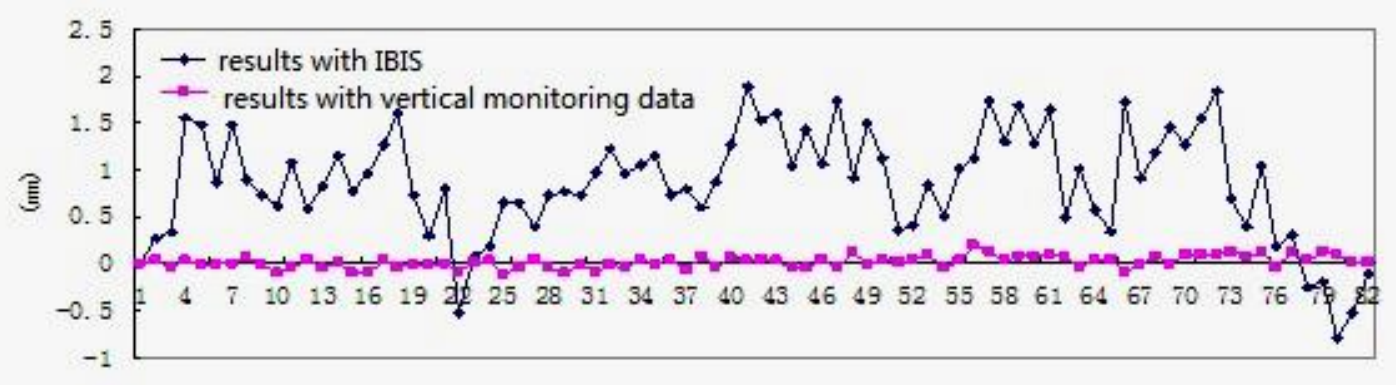

Figure 19: Results of IBIS-L data compared with vertical monitoring data.

\section{Conclusion}

GBInSAR technology is a useful tool for extracting deformation by virtue of radar interferometry technique, which has been applied in deformation monitoring for major projects such as dam, bridge and slope. Compared with traditional method, GBInSAR is a kind of potential monitoring technology with high precision, 2D imaging capability, monitoring in real time and all weather condition. According the atmospheric contribution to the phase, This paper proposes a approach to estimate atmospheric phase which should be removed by permanent scatters analysis. This technique has been proven to be effective in Hegeyan dam monitored continuously for 24 hours in this paper, and the displacement map for the dam can be obtained. Compared with vertical monitoring results, the monitoring accuracy of GBInSAR technology is fully capable of being applied in deformation monitoring for major projects such as dam(Bernard Ini G,2007;He Ning,2009).

\section{ACKNOWLEDGMENT}

This work has been partially supported by "the Open Foundation of Key Laboratory of Precise Engineering and Industry Surveying of National Administration of Surveying, Mapping and Geoinformation," (Grant No. PF2013-2), and also been funded by "The Scientific Research Innovation Projects of Ordinary University Graduate Students in Jiangsu Province," (Grant No. KYLX_0498). 


\section{REFERENCES}

Yue Jianping, Fang Lu, LI Ni, "Research advances of theory and technology in deformation monitoring," Bulletin of Surveying and Mapping, 2007(7).

Liao Mingsheng, Lin Hui, "Synthetic aperture radar interferometry — Principle and Signal Processing," Published by Surveying and Mapping Press, 2003.

Qiu Zhiwei, Zhang Lu, Liao Mingsheng, "An algorithm for spaceborne interferometric sar signal processing with coherence optimization," Geometrics And Information Science Of Wuhan University, 2010, 35(9), pp.1065-1068.

Strozzi T, Farina P, Corsini A, "Survey and monitoring of landslide displacements by means of L band satellite SAR interferometry," Landslides,2005,2(3), pp.193-201.

Noferini L, Pieraccini M, Mecatti D, "Using GBSAR technique to monitor slow moving landslide," Engineering Geology, 2007, 95, pp.88-98.

Luzi G, Noferini L, Mecatti D, Macaluso G, "Using a groundbased SAR interferometer and a terrestrial laser scanner to monitor a snow covered slope: results from an experimental data collection in Tyrol(Austria)," IEEE Trasactions on Geoscience and Remote Sensing,2009,47(2),pp.382-393.

Herrera G, Fernandez Merodo JA, Mulas J, Pastor M, Luzi G, "A landslide forecasting model using ground based SAR data: the portalet case study,"Engineering Geology, 2009, 105(3/4), pp.220-230.

Luzi G, Pieraccini M, Mecatti D, Noferini L, "Monitoring of an alpine glacier by means of ground based SAR interferometry," Geoscience and Remote Sensing Letters, IEEE, 2007, 4(3), pp.495-499.

Mario A, Giulia B, Alberto G, "Measurement of dam deformations by terrestrial interferometric techniques," Congress of the International Society for Photogrammetry and Remote Sensing in Beijing, ISPRS, 2008, pp.133-139.

D.Tarchi, H.Rudolf. "Remote monitoring of buildings using a ground-based SAR:Application to cultural heritage survey," Remote Sensing,2000,21(18), pp.3545-3551.

Devis Dei, Massimiliano Pieraccini, et al, "Detection of vertical bending and torsional movements of a bridge using a coherent radar," NDT\&E International, 2009(6), pp.741-747.

Pipia L, Fabregas X, Aguasca A,Lopez-Martinez C, Mallorqui J,Mora O, "A Subsidence Monitoring Project using a Polarimetric GB-SAR Sensor,” Workshop POLinSAR,2007(1), pp.22-26.

Leva D, Nico G, Tarchi D, Fortuny-Guasch J, Sieber AJ "Temporal analysis of a landslide by means of a ground-based SAR interferometer," IEEE Transactions on Geosciences and Remote Sensing, 2003,41(4), pp.745-752.

Kazunori Takahashi, Matsumoto M, Sato M. "Continuous Observation of Natural Disaster Affected Areas Using Ground-Based SAR Interferometry," Applied Earth Observations And Remote Sensing, 2013,6(3), pp.1-8.

G. Bernardini, Ricci P. "Dynamic Monitoring Of Civil Engineering Structures By Microwave Interferometer," Conceptual Approach to Structural Design Venice, 2007(6).

Devis Dei, Massimiliano Pieraccini, Fratini M, Atzeni C, Bartoli G. "Detection of vertical bending and torsional movements of a bridge using a coherent radar," NDT\&E International, 2009(7), pp.741-747.

Bol. Ciênc. Geod., sec. Artigos, Curitiba, v. 22, no1, p.35 -53, jan-mar, 2016. 
Noferini L, Pieraccini M, Mecatti D, Luzi G, Atzeni C, Tamburini A. "Permanent scatterers analysis for atmospheric correction in ground based SARInterferometry," IEEE Transactions on Geosciences and Remote Sensing. 2005,43(7), pp.152-157.

He Min, He Xiufeng, "Interferometrie synthetie aperture radar and its application to deformation monitoring," Hydropower Automation and Dam Monitoring, 2005,29(2).

Huang Qihuang, Zhang Lixiang, "Ground-based synthetic aperture radar interferometry and its application to deformation monitoring," Advances In Science And Technology Of Water Resources, 2011,31(3), pp.54-62

Strozzi T, Farina P, Corsini A, "Survey and monitoring of landslide displacements by means of L- band satellite SAR interferometry," Landslides, 2005, 2(3), pp.193-201.

L Pipia, X Fabregas, A. Albert, L. M. Carlos, "Atmospheric artifact compensation in Ground-Based DInSAR applications,” IEEE Geosci. Remote Sens. Letters, 2008, 5(1), pp.88-92

H. Lee, J. H. Lee, S. J. Cho, N. H. Sung and J. H. Kim, "An experiment of GB-SAR interferometric measurement of target displacement and atmospheric correction," IGARSS, 2008, pp. 240-243.

Linhsia Noferini, Massimiliano Pieraccini, D Mecatti, G Macaluso, "DEM by Ground-Based SAR Interferometry," IEEE Geoscience And Remote Sensing Letters, 2007, 4(4), pp.659-663.

Bernard Ini G, Ricc I P, Coppi F, "A Ground Based M icrowave Interferometer with Imaging Capabilities for Remote Measurements of Displacements," M GALAHAD workshop within the 7th Geometric Week and the "3rd International Geotelematics Fair ( GlobalGeo )", Barcelona, Spain, 2007, pp.20-23.

He Ning, Qi Yue, He Bin, Wang Zhangchun, "Application of movement and surveying radar in the surface displacement monitoring of dam," China Water Resources, 2009.08.

Recebido em maio de 2015.

Aceito em julho de 2015.

Bol. Ciênc. Geod., sec. Artigos, Curitiba, v. 22, nำ1, p.35 -53, jan-mar, 2016. 